\title{
EDITORIAL
}

\section{Chronotherapeutics (light and wake therapy) in affective disorders*}

The Committee on Chronotherapeutics was recently formed by the International Society for Affective Disorders (ISAD), which has asked us to provide a consensus review of chronotherapeutics (light and wake therapy) in affective disorders. We consider these non-pharmaceutical, biologically based therapies to be potentially powerful adjuvants ready for clinical application. We also stress the need for additional studies, both in-patient and out-patient, to broaden the evidence base for indications and efficacy.

The theme of adjuvant therapy is of increasing interest. Many of the lectures at the 2nd ISAD Meeting (Cancun, Mexico, March 2004) emphasized that combination treatments - such as cognitive behavioural therapy added to antidepressants (Paykel, 2004; Scott, 2004) - could help treat the residual symptoms that indeed portend relapse (Thase, 2004). The meeting highlighted expansion of interest in the development of new concepts for treating depressive illness (i.e. drug targets other than monoamines) - to wit: 'New antidepressants are needed and they are on their way' (Pinder, 2004). On a pragmatic plane, the World Health Organization (WHO) has placed emphasis on the "need to demonstrate that interventions are not only effective and sustainable, but also affordable' (Chisholm, 2004). The meeting symposia shared the realization that the long-sought, faster-acting, relapse-preventing antidepressants are still not at hand, and that the field must continue to pursue combinations of psychological and pharmacological interventions.

Missing from discussion, however, was consideration of light therapy and sleep deprivation, whose well-demonstrated efficacy - alone or in combination (Berger, 2004; Benedetti et al. $2004 a$; Martiny et al. 2004; Terman, 2004; Wu, 2004) - could fulfil the WHO mandates of affordability and sustainability. The apparent blindness to these treatments by the psychiatric mainstream most likely stems from the prevailing neuropharmacological paradigm, and - if we may face realities - the commercial drawback that they cannot be patented (Studwell, 2004). In spite of many fascinating recent advances in development of new classes of antidepressant drugs (Holden, 2003), they are not yet ready for clinical use. By contrast, chronobiological interventions are already available and offer prospects no less potent than any candidate drug (Wirz-Justice et al. 2004).

Chronotherapeutics - treatments based on the principles of circadian rhythm organization and sleep physiology - offers mental health practitioners a set of non-pharmaceutical, rapid and effective antidepressant modalities for monotherapy or as adjuvants to conventional medication. Here, we consider supplemental light exposure and sleep deprivation (more positively known as 'wake therapy') as first-line treatments for major depression.

Light therapy was first developed and has been established as the treatment of choice for winter seasonal affective disorder (SAD; Partonen \& Magnusson, 2001). The use of light therapy has expanded beyond SAD (Lam, 1998), with evidence for efficacy in premenstrual (Lam et al. 1999) and antepartum (Epperson et al. 2004) depression, bulimia nervosa (Blouin et al. 1996; Lam, 1998; Braun et al. 1999), as well as sleep-wake cycle disturbances [delayed and advanced sleep phase syndromes (Abbott, 2003; Reid et al. 2004) and Alzheimer's dementia (Skjerve et al. 2004)].

Evidence for the usefulness of these treatments for non-seasonal major depression is less clear, with both positive (Yamada et al. 1995) and lack of effects (Mackert et al. 1991) on record. Most studies have been of much shorter duration than required for testing new antidepressants, even

* Address for correspondence: Dr Anna Wirz-Justice, Centre for Chronobiology, University Psychiatric Hospitals, Wilhelm Klein Strasse 27, CH-4025 Basel, Switzerland. (Email: anna.wirz-justice@unibas.ch) 
though an early study found a significant $18 \%$ net benefit relative to placebo after only 1 week (Kripke et al. 1992). Controlled trials of light therapy for non-seasonal depression have been reviewed (Kripke, 1998) and are the focus of two recent meta-analyses (Tuunainen et al. 2004; Golden et al. in press). Cautious in their recommendations ('light therapy offers modest though promising antidepressive efficacy, especially when administered during the first week of treatment, in the morning, and as an adjunctive treatment to sleep deprivation responders' (Tuunainen et al. 2004, p. 1), these overviews emphasize the need for further studies. The first positive data for this next generation of studies is beginning to appear, e.g. light therapy in chronic depression (Goel et al. 2003; Terman, 2004) and bipolar depression (Benedetti et al. 2004a). The completion of the largest controlled, double-blind clinical trial to date of adjuvant bright light in non-seasonal major depression is auspicious (Martiny, 2004).

Neither drugs nor psychotherapy has overcome a time lag of at least 2 weeks before onset of clinically significant effect (Bech, 2002). In contrast, wake therapy, whether administered over the whole night or restricted to the second half of the night, provides astonishing responses - within hours - in approximately $60 \%$ of patients with major depression, independent of diagnostic subgroup (Wu \& Bunney, 1990; Leibenluft \& Wehr, 1992; Wirz-Justice \& Van den Hoofdakker, 1999; Berger et al. 2003). Wake therapy has been extensively studied since it was first reported more than 30 years ago, yet it has suffered a fate similar to that of orphan drugs (Wirz-Justice, 1998). Its antidepressant effect is usually brief; indeed, full or partial relapse usually follows recovery sleep or even short naps. Psychiatrists who tested wake therapy were surprised and impressed by the rapidity and the magnitude of response, particularly in patients with severe melancholia, but relegated the method to a back corner because of the burden of administration and almost certain rapid relapse. 'Should one show them paradise and then take it away?' one leading psychiatrist at the ISAD Meeting commented disparagingly. Nevertheless, the key finding of remarkably rapid major improvement remains important and unique. It is surprising that no drug company has sought a novel fast-acting antidepressant in this model of extended wakefulness.

Over the last decade, the Milano psychiatrists have carried out systematic studies of repeated allnight wake therapy to find a way to prevent relapse. The antidepressant response was successfully maintained with lithium salts (Szuba et al. 1994; Benedetti et al. 1999a), the 5-HT 1A $_{\text {antagonist }}$ pindolol (Smeraldi et al. 1999), phase advance of the sleep-wake cycle (Benedetti et al. 2001 a) and morning light therapy (Neumeister et al. 1996; Colombo et al. 2000). Wake therapy combined with light has been successfully self-administered by out-patients on concomitant antidepressant medication (Loving et al. 2002).

These studies demonstrate rapid and sustained antidepressant response in unipolar and - most strikingly-bipolar depressed patients. The switch rates to mania or hypomania are not exacerbated, and are similar to those observed with newer antidepressants (Colombo et al. 1999). In a collective with unipolar depression, the Freiburg group has focused on single-night wake therapy followed by a sleep phase advance with a 5-day stepwise return to normal sleep time. This strategy prevented relapse in two-thirds of wake-therapy responders, and, in a randomized, controlled trial, was more effective than sleep phase delays (Riemann et al. 1999). To make this kind of protocol more practicable, the phase advance has been reduced to 3 days, with similar results (Voderholzer et al. 2003). Given that sleepiness is quite high after a night awake, going to sleep earlier on the first night (17:00 hours) is easy for patients, and the protocol then shifts bedtime to 19:00 and 21:00 hours on subsequent nights. The method is now being used in a clinical trial that assigns patients to 'treatment as usual' or augmentation of single-night wake therapy with the 3-day sleep phase advance protocol combined with daily morning light. Initial results are promising (Wu, 2004).

Selective serotonin reuptake inhibitors (SSRIs) are effective in approximately $70 \%$ of patients with a major depressive episode, but usually require at least 2 weeks for significant clinical improvement. The combination of wake therapy and fluoxetine (Benedetti et al. 1997) or morning light and citalopram (Benedetti et al. 2003a) hastens and magnifies the antidepressant response, showing that both wake and light therapy are compatible with, and reinforce the effect of, 
Table 1. Circadian and sleep therapies for major depression

\begin{tabular}{|c|c|c|}
\hline & $\begin{array}{l}\text { Therapeutic } \\
\text { latency }\end{array}$ & $\begin{array}{l}\text { Response } \\
\text { duration }\end{array}$ \\
\hline Total sleep deprivation (TSD) & Hours & $\sim 1$ day \\
\hline $\begin{array}{l}\text { Partial sleep deprivation (PSD) } \\
\text { (2nd half of the night) }\end{array}$ & Hours & $\sim 1$ day \\
\hline Repeated TSD or PSD & Hours & Days/weeks \\
\hline Repeated TSD or PSD with antidepressants & Hours & Weeks/months \\
\hline Phase advance of the sleep-wake cycle & $\sim 3$ days & $1-2$ weeks \\
\hline TSD followed by sleep phase advance & Hours & $1-2$ weeks \\
\hline $\begin{array}{l}\text { Single or repeated TSD or PSD followed by } \\
\text { light therapy }\end{array}$ & Hours & Weeks \\
\hline $\begin{array}{l}\text { Single or repeated TSD or PSD followed by } \\
\text { phase advance and light therapy }\end{array}$ & Hours & Weeks \\
\hline $\begin{array}{l}\text { Single or repeated TSD or PSD } \\
\text { combined with lithium, pindolol, or SSRIs }\end{array}$ & Hours & Months \\
\hline Light therapy (winter seasonal MDD) & Days & Weeks/months \\
\hline Light therapy (non-seasonal MDD) & Weeks & Weeks/months \\
\hline Light therapy with SSRIs (non-seasonal MDD) & $1-2$ weeks & Weeks/months \\
\hline Dark or rest therapy (for rapid cycling or mania) & Days & $\begin{array}{l}\text { Throughout } \\
\text { maintenance } \\
\text { of treatment }\end{array}$ \\
\hline
\end{tabular}

serotonergic antidepressants. Indeed, many biological studies of light therapy in winter depression have addressed the importance of the role of classical neurotransmitters in addition to circadian phase advance shifts for therapeutic response (Sack et al. 1990; Terman et al. 2001), providing solid evidence for both mechanisms of action (Lam et al. 2001). Genetic variations of the serotonin transporter exert similar influences on the response to serotonergic drugs (e.g. Smeraldi et al. 1998), wake therapy (Benedetti et al. 1999b) and light therapy (Benedetti et al. 2003 b). Individual genetic characteristics of the molecular mechanisms of the biological clock are also determinants of the same core features of mood disorders, including age at onset (Benedetti et al. 2004b), recurrence (Benedetti et al. 2003 c), response to wake therapy (Benedetti et al. 2004b), and depressive insomnia (Serretti et al. 2003) and its response to drugs (Serretti et al. in press). Such parallel findings point to an intimate relationship between the neurotransmitter systems targeted by drugs and the circadian rhythms targeted by chronotherapeutics.

The latest large controlled study compares 5 weeks of adjunctive bright white light with placebo dim red light in sertraline-treated patients with non-seasonal major depression (Martiny, 2004). With a response rate of $66 \cdot 7 \% v .40 \cdot 7 \%$, and remission rate of $41 \cdot 7 \% v .14 \cdot 8 \%$ for bright $v$. dim light, we now have convincing evidence of specific efficacy using stringent clinical trial methodology. We hope this will provide impetus to other researchers to investigate the potential of light therapy as an adjuvant in their depressive populations.

The various chronotherapeutic modalities (and their combinations) studied thus far are summarized in Table 1. Initial intriguing studies showing that long dark nights can stop rapid cycling (Wehr et al. 1998; Wirz-Justice et al. 1999) or diminish manic symptoms (Barbini et al. 2005) may add another chronobiological treatment to the repertory.

The public zeitgeist favours non-pharmaceutical treatments. Patients accept and often prefer them. Unlike many touted remedies, however, wake and light therapy are not alternative, unproved, or soft. Wake and light therapy provide flexible opportunities for multimodal treatment as adjuvants with negligible side-effects or untoward interactions with ongoing medication. The few systematic reports of side-effects suggest that these treatments are safe, with only relative counterindications that can be evaluated with careful psychopathological and somatic diagnosis and observation throughout treatment. In these days of managed care, their speed of action is an important consideration. Indeed, length of hospitalization can be reduced. Retrospective examination of more than 800 in-patients treated for bipolar depression in a common psychiatric 
hospital setting found that the combination of multiple wake therapy with usual drug treatment led to discharge an average of 3 days earlier than with drug treatment alone (F. Benedetti, unpublished data). Mere increased exposure to natural light in sunny hospital rooms has also resulted in an average 3-day advantage compared with dimmer rooms (Beauchemin \& Hays, 1996; Benedetti et al. $2001 b)$.

It is time for wake and light therapy to be incorporated into mainstream psychiatry. To consider them mere curiosities outside the paradigm wastes resources and prolongs suffering. Building on the example of the American Psychiatric Association (Golden et al. in press), national psychiatric associations should exert clinical leadership and develop standards of practice for chronotherapeutics. It would be a shame to wait for the insurance industry to impose these measures based purely on the cost considerations of managed care.

\section{SUMMARY}

The Committee on Chronotherapeutics, delegated by the International Society for Affective Disorders (ISAD), makes the following recommendations after reviewing the evidence as of November 2004.

(1) Wake therapy is the most rapid antidepressant available today: approximately $60 \%$ of patients, independent of diagnostic subtype, respond with marked improvement within hours. Treatment can be a single or repeated sleep deprivation, total (all night) or partial (second half of the night). Relapse can be prevented by daily light therapy, concomitant administration of SSRIs, lithium (for bipolar patients), or a short phase advance of sleep over 3 days following a single night of wake therapy. Combinations of these interventions show great promise.

(2) Light therapy is effective for major depression-not only for the seasonal subtype. As an adjuvant to conventional antidepressants in unipolar patients, or lithium in bipolar patients, morning light hastens and potentiates the antidepressant response. Light therapy shows benefit even for patients with chronic depression of 2 years or more, outperforming their weak response to drugs. This method provides a viable alternative for patients who refuse, resist or cannot tolerate medication, or for whom drugs may be contraindicated, as in antepartum depression.

(3) Given the urgent need for new strategies to treat patients with residual depressive symptoms, clinical trials of wake therapy and/or adjuvant light therapy, coupled with follow-up studies of long-term recurrence, are a high priority.

ANNA WIRZ-JUSTICE, FRANCESCO BENEDETTI, MATHIAS BERGER, RAYMOND W. LAM, KLAUS MARTINY, MICHAEL TERMAN AND JOSEPH C. WU

(International Society for Affective Disorders, Committee on Chronotherapeutics in Affective Disorders)

\section{DECLARATION OF INTEREST}

None.

\section{REFERENCES}

Abbott, A. (2003). Restless nights, listless days. Nature 425, 896898.

Barbini, B., Benedetti, F., Colombo, C., Dotoli, D., Bernasconi, A., Cigala-Fulgosi, M., Florita, M. \& Smeraldi, E. (2005). Dark therapy for mania: a pilot study. Bipolar Disorders 7, 98-101.
Beauchemin, K. M. \& Hays, P. (1996). Sunny hospital rooms expedite recovery from severe and refractory depressions. Journal of Affective Disorders 40, 49-51.

Bech, P. (2002). Pharmacological treatment of depressive disorders: a review. In Depressive Disorders (2nd edn) (ed. M. Maj and N. Sartorius), pp. 89-128. John Wiley: Chichester, UK. 
Benedetti, F., Barbini, B., Campori, E., Fulgosi, M. C., Pontiggia, A. \& Colombo, C. $(2001 a)$. Sleep phase advance and lithium to sustain the antidepressant effect of total sleep deprivation in bipolar depression: new findings supporting the internal coincidence model? Journal of Psychiatric Research 35, 323-329.

Benedetti, F., Barbini, B., Lucca, A., Campori, E., Colombo, C. \& Smeraldi, E. (1997). Sleep deprivation hastens the antidepressant action of fluoxetine. European Archives of Psychiatry and Clinical Neuroscience 247, 100-103.

Benedetti, F., Colombo, C., Barbini, B., Campori, E. \& Smeraldi, E. $(1999 a)$. Ongoing lithium treatment prevents relapse after total sleep deprivation. Journal of Clinical Psychopharmacology $\mathbf{1 9}$ $240-245$.

Benedetti, F., Colombo, C., Barbini, B., Campori, E. \& Smeraldi, E. (2001 b). Morning sunlight reduces length of hospitalization in bipolar depression. Journal of Affective Disorders 62 , 221-223.

Benedetti, F., Colombo, C., Bernasconi, A., Barbini, B., Fulgosi, M. C., Pontiggia, A. \& Smeraldi, E. (2004a). Chronobiological treatments of bipolar depression. In The International Society for Affective Disorders (ISAD), 2nd Biennial Conference, Cancun, Mexico. Journal of Affective Disorders 78 (Suppl. 1), S14.

Benedetti, F., Colombo, C., Pontiggia, A., Bernasconi, A., Florita, M. \& Smeraldi, E. $(2003 a)$. Morning light treatment hastens the antidepressant effect of citalopram: a placebo-controlled trial. Journal of Clinical Psychiatry 64, 648-653.

Benedetti, F., Colombo, C., Serretti, A., Lorenzi, C., Pontiggia, A., Barbini, B. \& Smeraldi, E. (2003b). Antidepressant effects of light therapy combined with sleep deprivation are influenced by a functional polymorphism within the promoter of the serotonin transporter gene. Biological Psychiatry 54, 687-692.

Benedetti, F., Serretti, A., Colombo, C., Barbini, B., Lorenzi, C., Campori, E. \& Smeraldi, E. $(2003 c)$. Influence of CLOCK gene polymorphism on circadian mood fluctuation and illness recurrence in bipolar depression. American Journal of Medical Genetics B123, 23-26.

Benedetti, F., Serretti, A., Colombo, C., Campori, E., Barbini, B., di Bella, D. \& Smeraldi, E. (1999 b). Influence of a functional polymorphism within the promoter of the serotonin transporter gene on the effects of total sleep deprivation in bipolar depression. American Journal of Psychiatry 156, 1450-1452.

Benedetti, F., Serretti, A., Colombo, C., Lorenzi, C., Tubazio, V. \& Smeraldi, E. (2004b). A glycogen synthase kinase 3-b promoter gene SNP is associated with age at onset and response to total sleep deprivation in bipolar depression. Neuroscience Letters 368, 123126.

Berger, M. (2004). Sleep phase advances as a fast-acting antidepressive strategy. In The International Society for Affective Disorders (ISAD), 2nd Biennial Conference, Cancun, Mexico. Journal of Affective Disorders 78 (Suppl. 1), S15.

Berger, M., van Calker, D. \& Riemann, D. (2003). Sleep and manipulations of the sleep-wake rhythm in depression. Acta Psychiatrica Scandinavica (Suppl.), 418, 83-91.

Blouin, A. G., Blouin, J. H., Iversen, H., Carter, J., Goldstein, C., Goldfield, G. \& Perez, E. (1996). Light therapy in bulimia nervosa: a double-blind, placebo-controlled study. Psychiatry Research $\mathbf{2 8}$ $1-9$.

Braun, D. L., Sunday, S. R., Fornari, V. M. \& Halmi, K. A. (1999). Bright light therapy decreases winter binge frequency in women with bulimia nervosa: a double-blind, placebo-controlled study. Comprehensive Psychiatry 40, 442-448.

Chisholm, D. (2004). Avertable burden of affective disorders: a global cost-effectiveness analysis. In The International Society for Affective Disorders (ISAD), 2nd Biennial Conference, Cancun, Mexico. Journal of Affective Disorders 78 (Suppl. 1), S21.

Colombo, C., Benedetti, F., Barbini, B., Campori, E. \& Smeraldi, E. (1999). Rate of switch from depression into mania after therapeutic sleep deprivation in bipolar depression. Psychiatry Research 86, 267-270.

Colombo, C., Lucca, A., Benedetti, F., Barbini, B., Campori, E. \& Smeraldi, E. (2000). Total sleep deprivation combined with lithium and light therapy in the treatment of bipolar depression: replication of main effects and interaction. Psychiatry Research 95, 43-53.

Epperson, C. N., Terman, M., Terman, J. S., Hanusa, B. H., Oren, D. A., Peindl, K. S. \& Wisner, K. L. (2004). Randomized clinical trial of bright light therapy for antepartum depression: preliminary findings. Journal of Clinical Psychiatry $\mathbf{6 5}$, 421- 425 .

Goel, N., Terman, J. S., Macchi, M. M., Stewart, J. W. \& Terman, M. (2003). A placebo-controlled trial of light and negative ion treatment for chronic depression: preliminary results. Chronobiology International 20, 1207-1209.

Golden, R. N., Gaynes, B. N., Ekstrom, R. D., Hamer, R. M., Jacobsen, F. M., Suppes, T., Wisner, K. L. \& Nemeroff, C. B. (in press). The efficacy of light therapy in the treatment of mood disorders: a review and meta-analysis of the evidence. American Journal of Psychiatry.

Holden, C. (2003). Future brightening for depression treatments. Science 302, 810-813.

Kripke, D. F. (1998). Light treatment for nonseasonal depression: speed, efficacy, and combined treatment. Journal of Affective Disorders 49, 109-117.

Kripke, D. F., Mullaney, D. J., Klauber, M. R., Risch, S. C. \& Gillin, J. C. (1992). Controlled trial of bright light for nonseasonal major depressive disorders. Biological Psychiatry 31, 119-134.

Lam, R. W. (ed.) (1998). Seasonal Affective Disorder and Beyond. Light Treatment for SAD and Non-SAD Conditions. American Psychiatric Press: Washington, DC.

Lam, R. W., Carter, D., Misri, S., Kuan, A. J., Yatham, L. N. \& Zis, A. P. (1999). A controlled study of light therapy in women with late luteal phase dysphoric disorder. Psychiatry Research $\mathbf{8 6}$, 185-192.

Lam, R. W., Tam, E. M., Yatham, L. N., Shiah, I. S. \& Zis, A. P. (2001). Seasonal depression: the dual vulnerability hypothesis revisited. Journal of Affective Disorders 63, 123-132.

Leibenluft, E. \& Wehr, T. A. (1992). Is sleep deprivation useful in the treatment of depression? American Journal of Psychiatry 149 $159-168$.

Loving, R. T., Kripke, D. F. \& Shuchter, S. R. (2002). Bright light augments antidepressant effects of medication and wake therapy. Depression and Anxiety 16, 1-3.

Mackert, A., Volz, H. P., Stieglitz, R. D. \& Müller-Oerlinghausen, B. (1991). Phototherapy in nonseasonal depression. Biological Psychiatry 30, 257-268.

Martiny, K. (2004). Adjunctive bright light in non-seasonal major depression. Acta Psychiatrica Scandinavica 425 (Suppl.), 7-28

Martiny, K., Lunde, M., Undén, M., Dam, H. \& Bech, P. (2004) Adjunctive bright light in non-seasonal major depression. In The International Society for Affective Disorders (ISAD), 2nd Biennial Conference, Cancun, Mexico. Journal of Affective Disorders 78 (Suppl. 1), S16.

Neumeister, A., Goessler, R., Lucht, M., Kapitany, T., Bamas, C. \& Kasper, S. (1996). Bright light therapy stabilizes the antidepressant effect of partial sleep deprivation. Biological Psychiatry 39, 16-21.

Partonen, T. \& Magnusson, A. (eds) (2001). Seasonal Affective Disorder. Practice and Research. Oxford University Press: Oxford.

Paykel, E. (2004). Long-term outcome of depression: a problem. In The International Society for Affective Disorders (ISAD), 2nd Biennial Conference, Cancun, Mexico. Journal of Affective Disorders 78 (Suppl. 1), S2.

Pinder, R. M. (2004). Do we need more antidepressants? In The International Society for Affective Disorders (ISAD), 2nd Biennial Conference, Cancun, Mexico. Journal of Affective Disorders 78 (Suppl. 1), S8.

Reid, K. J., Chang, A. M. \& Zee, P. C. (2004). Circadian rhythm sleep disorders. Medical Clinics of North America $\mathbf{8 8}$ 631-651.

Riemann, D., König, A., Hohagen, F., Kiemen, A., Voderholzer, U., Backhaus, J., Bunz, J., Wesiack, B., Hermle, L. \& Berger, M. 
(1999). How to preserve the antidepressive effect of sleep deprivation: a comparison of sleep phase advance and sleep phase delay. European Archives of Psychiatry and Clinical Neuroscience 249, 231-237.

Sack, R. L., Lewy, A. J., White, D. M., Singer, C. M., Fireman, M. J. \& Vandiver, R. (1990). Morning vs evening light treatment for winter depression. Evidence that the therapeutic effects of light are mediated by circadian phase shifts. Archives of General Psychiatry 47, 343-351.

Scott, J. (2004). Benefits of CBT in individuals with bipolar disorders. In The International Society for Affective Disorders (ISAD), 2nd Biennial Conference, Cancun, Mexico. Journal of Affective Disorders 78 (Suppl. 1), S13.

Serretti, A., Benedetti, F., Mandelli, L., Lorenzi, C., Pirovano, A., Colombo, C. \& Smeraldi, E. (2003). Genetic dissection of psychopathological symptoms: insomnia in mood disorders and CLOCK gene polymorphism. American Journal of Medical Genetics B121, $35-38$.

Serretti, A., Cusin, C., Benedetti, F., Mandelli, L., Pirovano, A., Zanardi, R., Colombo, C. \& Smeraldi, E. (in press). Insomnia improvement during antidepressant treatment is associated with CLOCK gene polymorphism. American Journal of Medical Genetics.

Skjerve, A., Bjorvatn, B. \& Holsten, F. (2004). Light therapy for behavioural and psychological symptoms of dementia. International Journal of Geriatric Psychiatry 19, 516-522.

Smeraldi, E., Benedetti, F., Barbini, B., Campori, E. \& Colombo, C. (1999). Sustained antidepressant effect of sleep deprivation combined with pindolol in bipolar depression. A placebo-controlled trial. Neuropsychopharmacology 20, 380-385.

Smeraldi, E., Zanardi, R., Benedetti, F., Di Bella, D., Perez, J. \& Catalano, M. (1998). Polymorphism within the promoter of the serotonin transporter gene and antidepressant efficacy of fluvoxamine. Molecular Psychiatry 3, 508-511.

Szuba, M. P., Baxter, L. R. J., Altshuler, L. L., Allen, E. M., Guze, B. H., Schwartz, J. M. \& Liston, E. H. (1994). Lithium sustains the acute antidepressant effects of sleep deprivation: preliminary findings from a controlled study. Psychiatry Research 51, 283-295.

Studwell, J. (2004). All sleepless and light. Financial Times, 23 October 2004.

Terman, J.S., Terman, M., Lo, E.S. \& Cooper, T. B. (2001). Circadian time of morning light administration and therapeutic response in winter depression. Archives of General Psychiatry 58, 69-75.
Terman, M. (2004). Light and negative air ion treatment for chronic depression. In The International Society for Affective Disorders (ISAD), 2nd Biennial Conference, Cancun, Mexico. Journal of Affective Disorders 78 (Suppl. 1), S15.

Thase, M. (2004). How to achieve more remission. In The International Society for Affective Disorders (ISAD), 2nd Biennial Conference, Cancun, Mexico. Journal of Affective Disorders 78 (Suppl. 1), S9.

Tuunainen, A., Kripke, D. F. \& Endo, T. (2004). In The Cochrane Library, vol. 2. John Wiley \& Sons Ltd: Chichester, UK. CD004050.

Voderholzer, U., Valerius, G., Schaerer, L., Riemann, D., Giedke, H., Schwarzler, F., Berger, M. \& Wiegand, M. (2003). Is the antidepressive effect of sleep deprivation stabilized by a three day phase advance of the sleep period? A pilot study. European Archives of Psychiatry and Clinical Neuroscience 253, 68-72.

Wehr, T. A., Turner, E. H., Shimada, J. M., Lowe, C. H., Barker, C. \& Leibenluft, E. (1998). Treatment of rapidly cycling bipolar patient by using extended bed rest and darkness to stabilize the timing and duration of sleep. Biological Psychiatry 43, 822-828.

Wirz-Justice, A. (1998). Why is sleep deprivation an orphan drug? Psychiatry Research 81, 281-282.

Wirz-Justice, A., Quinto, C., Cajochen, C., Werth, E. \& Hock, C. (1999). A rapid-cycling bipolar patient treated with long nights, bedrest, and light. Biological Psychiatry 45, 10751077 .

Wirz-Justice, A., Terman, M., Oren, D. A., Goodwin, F. K., Kripke, D. F., Whybrow, P. C., Wisner, K. L., Wu, J. C., Lam, R. W., Berger, M., Danilenko, K. V., Kasper, S., Smeraldi, E., Takahashi, K., Thompson, C. \& van den Hoofdakker, R. H. (2004). Brightening depression. Science 303, 467-469.

Wirz-Justice, A. \& Van den Hoofdakker, R. H. (1999). Sleep deprivation in depression: what do we know, where do we go? Biological Psychiatry 46, 445-453.

Wu, J. C. (2004). Chronobiological augmentation of sleep deprivation as an antidepressant intervention. In The International Society for Affective Disorders (ISAD), 2nd Biennial Conference, Cancun, Mexico. Journal of Affective Disorders 78 (Suppl. 1), S15.

Wu, J. C. \& Bunney, W. E. (1990). The biological basis of an antidepressant response to sleep deprivation and relapse: review and hypothesis. American Journal of Psychiatry 147, 14-21.

Yamada, N., Martin-Iverson, M. T., Daimon, K., Tsujimoto, T. \& Takahashi, S. (1995). Clinical and chronobiological effects of light therapy. Biological Psychiatry 37, 866-873. 